\title{
Hydrogen Sulphide Production by Yeast under Conditions of Methionine, Pantothenate or Vitamin $B_{6}$ Deficiency
}

\author{
By T. WAINWRIGHT \\ Research Laboratory, Arthur Guinness Son and Co. (Dublin) Ltd, \\ St James's Gate, Dublin 8, Ireland
}

(Accepted for publication 23 December 1969)

\begin{abstract}
SUMMAR Y
Methionine-requiring mutants of Saccharomyces cerevisiae produce large amounts of hydrogen sulphide from sulphate, sulphite or thiosulphate when grown in the presence of suboptimum concentrations of methionine. $O$ Acetylhomoserine and homocysteine act like methionine with a methioninerequiring mutant which can use them for growth. Wild-type strains of $S$. cerevisiae and $S$. carlsbergensis also form large amounts of hydrogen sulphide from inorganic sulphur sources when the yeast is deficient in either pantothenate or vitamin $\mathbf{B}_{6}$. This excess sulphide production is inhibited by methionine or its immediate precursors, suggesting that both vitamins are required for methionine biosynthesis. $O$-Acetylhomoserine is a normal precursor of homocysteine and methionine in $S$. cerevisiae and $S$. carlsbergensis. The effect of pantothenate on sulphide production by these yeasts is probably due to its involvement in the formation of $O$-acetylhomoserine.
\end{abstract}

\section{INTRODUCTION}

Pantothenate-deficient yeasts produce large amounts of sulphide from inorganic sulphur compounds (Kodaira, Ito \& Uemura, 1958). With all strains tested, and not merely Saccharomyces species, yeasts which require pantothenate for growth produce abnormally large amounts of sulphide when grown with suboptimal concentrations of pantothenate (Wainwright, 1962). This effect of pantothenate deficiency has been reported only with yeasts and not with other micro-organisms.

A number of hypotheses have been suggested to explain the action of pantothenate, but none is entirely satisfactory and all propose a rather indirect role for the vitamin. Wiebers \& Garner (1967) showed that homocysteine, which is considered to be a methionine precursor in yeast, is formed by yeast enzyme preparations from $O$-acetylhomoserine and hydrogen sulphide in the presence of pyridoxal phosphate. One methionine-requiring mutant of Saccharomyces cerevisiae has also been described which grows on $O$-acetylhomoserine and apparently lacks homoserine transacetylase (de Robichon-Szulmajster, 1967; de Robichon-Szulmajster \& Cherest, 1967). The present work was undertaken to determine if the effect of pantothenate is due to its involvement, presumably as coenzyme $\mathrm{A}$, in the biosynthesis of $O$-acetylhomoserine.

\section{METHODS}

Organisms. Saccharomyces cerevisiae Guinness strain II 64 was used in most of the experiments. Saccharomyces carlsbergensis NCYC4228 is a yeast employed in the laboratory for vitamin $\mathrm{B}_{6}$ assays. Saccharomyces cerevisiae cC92-17A (lacking 
homoserine transacetylase) and $S$. cerevisiae ME-8 (lacking homocysteine synthetase) were kindly supplied by Dr H. de Robichon-Szulmajster, S. cerevisiae ME-3 by Dr L. W. Parks and the thiosulphate-utilizing mutants of $S$. cerevisiae 6, 2 I and 24 by $\mathrm{Dr} \mathrm{N}$. Naiki. The succinate-requiring mutant of Escherichia coli, w I485-suc-I, was obtained from Dr J. K. Guest and the pantothenate-requiring mutants of $E$. coli from the late Professor D. D. Woods.

Growth measurement. Growth was measured with an EEL colorimeter (Evans Electroselenium Ltd., Harlow, Essex) fitted with a neutral density filter. Calibration curves were made relating dry weight of organism and colorimeter reading.

Media. The basal liquid medium for yeast growth contained glucose, $50 \mathrm{~g}$; $\left(\mathrm{NH}_{4}\right)_{2} \mathrm{SO}_{4}, 2.5 \mathrm{~g}$.; $\mathrm{KCl}, 425 \mathrm{mg}$.; $\mathrm{KH}_{2} \mathrm{PO}_{4}, 275 \mathrm{mg}$; $\mathrm{MgSO}_{4} .7 \mathrm{H}_{2} \mathrm{O}$, $225 \mathrm{mg}$.; $\mathrm{CaCl}_{2} .2 \mathrm{H}_{2} \mathrm{O}$, I25 mg.; $\mathrm{MnSO}_{4}, 2.5 \mathrm{mg}$.; $\mathrm{FeSO}_{4}, 2.5 \mathrm{mg}$.; potassium citrate, $5 \mathrm{~g}$.; citric acid, I g.; biotin, $0.1 \mathrm{mg}$; inositol, $25 \mathrm{mg}$; thiamin, $0.5 \mathrm{mg}$.; distilled water to I 1.; pH 5.2. Unless otherwise stated the medium also contained $2 \mathrm{mg}$. calcium pantothenate and $0.5 \mathrm{mg}$. pyridoxine hydrochloride/1. In experiments on thiosulphate reduction to sulphide, the inorganic sulphate constituents were replaced by the corresponding chlorides and $4 \mathrm{~mm}$ thiosulphate was included in the medium. The basal medium for the two methionine-requiring mutants was supplemented with $20 \mathrm{mg}$. adenine, Io $\mathrm{mg}$. uracil and, except when stated, $300 \mathrm{mg}$. methionine/1.

The basal medium for Escherichia coli was that of Davis \& Mingioli (1950). Calcium pantothenate $\left(5 \times \mathrm{IO}^{-7} \mathrm{M}\right)$ was used to obtain full growth of the pantothenate-requiring mutants and $4 \mathrm{~mm}$ succinate for the succinate-requiring mutant.

Growth conditions. Yeast growth experiments were performed using $20 \mathrm{ml}$. quantities of medium in $50 \mathrm{ml}$. conical flasks incubated statically at $24^{\circ}$ for about $42 \mathrm{hr}$. The flasks were inoculated with a suspension of washed organisms equivalent to $0.9 \mathrm{mg}$. dry wt of yeast. This was derived from a $42 \mathrm{hr}$ subculture on a suitable liquid medium as indicated in the section of Results.

Bacterial growth experiments were performed at $30^{\circ}$ using $20 \mathrm{ml}$. quantities in static $50 \mathrm{ml}$. flasks. The inoculum, derived from liquid subculture in basal medium containing enough supplement to allow full growth, was equivalent to $0.4 \mu \mathrm{g}$. dry wt.

Cell suspensions. Organisms were subcultured in basal medium with $40 \mu \mathrm{g}$. calcium pantothenate/l. Washed organisms were suspended to give $9 \mathrm{mg}$. dry wt $/ \mathrm{ml}$. in a medium, $\mathrm{pH} 5^{\circ} \mathrm{O}$, containing Io g. glucose, $50 \mathrm{mg}$. $\mathrm{MgCl}_{2}, 24 \cdot 3 \mathrm{ml}$. O. I M-citric acid, $25.7 \mathrm{ml}$. $0.2 \mathrm{M}^{-\mathrm{Na}_{2}} \mathrm{HPO}_{4}$ and $50 \mathrm{ml}$. water. Three ml. quantities of this suspension were incubated with $0.4 \mathrm{ml} .2 \%(\mathrm{w} / \mathrm{v})$ zinc acetate and substrates in $\mathrm{I} \cdot 0 \mathrm{ml}$. water at $30^{\circ}$ on an orbital shaker at I $5 \mathrm{rev} . / \mathrm{min}$.

Hydrogen sulphide determination. Hydrogen sulphide was determined by the formation of methylene blue (Brenner, Owades \& Golyzniak, I954). The results presented here were obtained from experiments in which $0.2 \%(\mathrm{w} / \mathrm{v})$ zinc acetate was present in the medium throughout the growth or incubation period. At the end of the incubation, the medium was acidified and, after the addition of a drop of capryl alcohol, nitrogen gas was blown through the culture flask for $2 \mathrm{hr}$ to displace hydrogen sulphide through a capillary tube into a $2 \%(\mathrm{w} / \mathrm{v})$ zinc acetate trap. The sulphide content of the trap was then determined.

Since it is known that heavy-metal ions can under certain conditions markedly increase the amounts of hydrogen sulphide formed by yeast (Rankine, I963; Lawrence \& Cole, 1968) many of the results have been checked by omitting zinc acetate from the 
culture medium and using either a closed vessel or one with an external zinc acetate trap. The results were never qualitatively different from those obtained with zinc ions in the medium, but the quantities of hydrogen sulphide recovered were much lower and much more variable, probably due to oxidation of the sulphide formed.

Chemicals. $O$-Acetyl-DL-homoserine was prepared by the method of Nagai \& Flavin (1967). Other chemicals were the best grade commercially available.

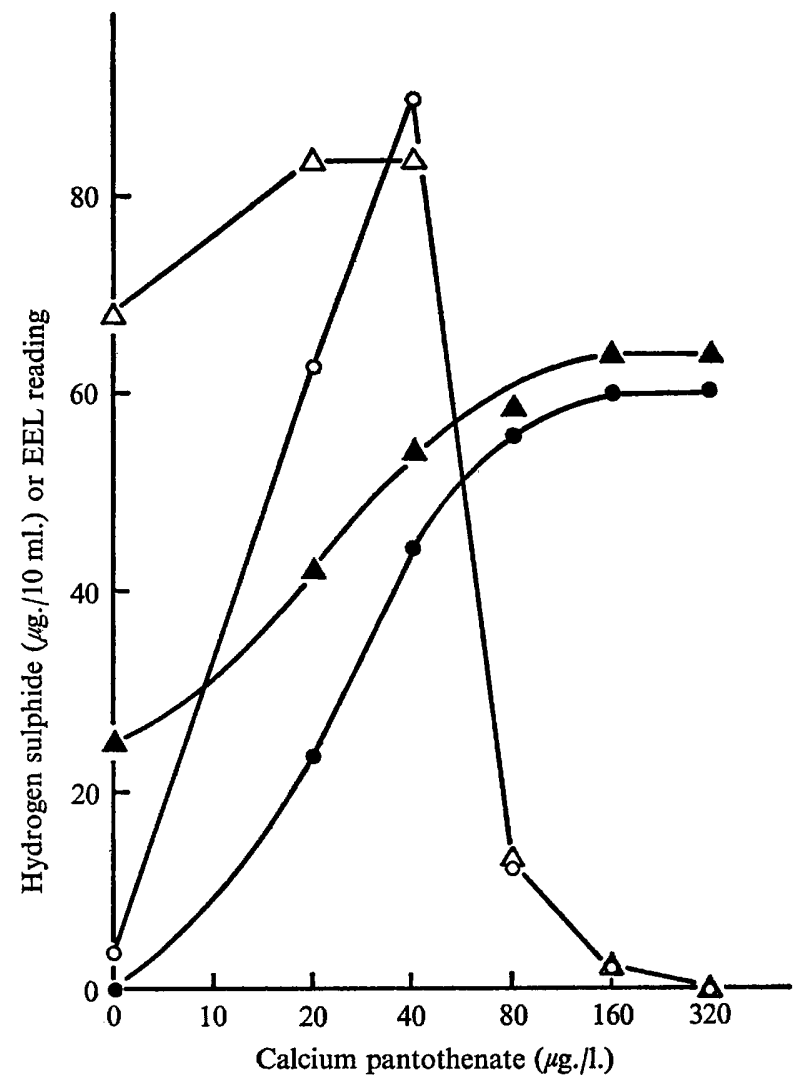

Fig. I. Growth and $\mathrm{H}_{2} \mathrm{~S}$ production by pantothenate-deficient Saccharomyces cerevisiae. $O$ Indicates hydrogen sulphide production with inoculum grown on $10 \mu \mathrm{g}$. pantothenate/l., and the corresponding EEL reading; $\triangle$ indicates hydrogen sulphide production with inoculum grown on $320 \mu \mathrm{g}$. pantothenate $/ 1$, and $\Delta$ the corresponding EEL reading.

\section{RESULTS}

Effect of supplements on hydrogen sulphide production by wild-type strains

\section{Pantothenate}

Growth of the yeast and the amount of sulphide formed depend on the pantothenate concentration in the medium (Fig. I). With sufficient pantothenate ( $>160 \mu \mathrm{g}$. $/ 1$.) no hydrogen sulphide is formed. With lower concentrations there is a peak production of sulphide usually at about $40 \mu \mathrm{g}$. pantothenate $/ 1$. The exact shape of the production curve depends on the concentration of pantothenate present during growth of the inoculum A more deficient inoculum gives less growth at low pantothenate concentrations 
and consequently less hydrogen sulphide. This dependence of sulphide production on the amount of growth is shown if the growth is limited at any one suboptimal concentration of pantothenate by the amount of glucose, sulphate or nitrogen source available, or if the course of growth and hydrogen sulphide production is plotted against time. It is essential to allow for this dependence on the amount of growth when considering the effect of added compounds such as methionine on the amount of hydrogen sulphide produced.

\section{Methionine}

Kodaira \& Uemura (1960) using Saké yeast claimed that a variety of amino acids, notably methionine and leucine, decreased the amount of sulphide formed by pantothenate-deficient yeast. Methionine under certain conditions inhibits sulphide formation by brewer's yeast but the effect depends both on the methionine concentration and on the yeast strain. As shown in Table I, with some yeasts increasing concentrations of methionine progressively suppress the amount of sulphide formed, although they do not inhibit hydrogen sulphide formation completely. With other yeasts, although higher concentrations of methionine inhibit hydrogen sulphide formation, below a certain concentration methionine actually stimulates production (Table I).

Table I. Effect of methionine on hydrogen sulphide production by different strains of pantothenate-deficient Saccharomyces cerevisiae

$\begin{array}{cccc}\begin{array}{c}\text { Yeast } \\ \text { strain }\end{array} & \begin{array}{c}\text { DL-Methionine } \\ (\mathrm{M})\end{array} & \begin{array}{c}\text { Growth } \\ \text { (g. dry wt/1.) }\end{array} & \begin{array}{c}\text { Hydrogen sulphide } \\ (\mathrm{mg} . / 1 .)\end{array} \\ \text { II64 } & 0 & 3 \cdot 1 & 4.6 \\ & 2 \times 10^{-3} & 2 \cdot 7 & 3.35 \\ & 5 \times 10^{-3} & 2 \cdot 7 & 1 \cdot 35 \\ \text { I408 } & 10^{-2} & 2 \cdot 35 & 0.6 \\ & 0 & 2 \cdot 7 & 0.875 \\ & 2 \times 10^{-3} & 2.6 & 1 \cdot 35 \\ & 5 \times 10^{-3} & 2.35 & 0.275 \\ & 10^{-2} & 2 \cdot 3 & 0.125\end{array}$

Two Guinness strains of Saccharomyces cerevisiae were grown 44 hr in basal medium containing $40 \mu \mathrm{g}$. calcium pantothenate/l., using inocula previously grown in the same medium with no methionine.

Both types of effect-the progressive inhibition of hydrogen sulphide formation at higher methionine concentrations and the stimulation at intermediate concentrationshave been obtained with several strains of Saccharomyces cerevisiae. With $5 \mathrm{~mm}$ DL-methionine, inhibition occurs in all yeasts. The D-isomer by itself is inactive, and $\mathrm{L}$-methionine is twice as active as DL-methionine on a molar basis.

\section{O-Acetylhomoserine, homoserine and homocysteine}

Table 2 shows that $O$-acetyl-DL-homoserine suppresses hydrogen sulphide formation by yeast. On a molar basis it is equivalent to DL-methionine. Homoserine, the precursor of $O$-acetylhomoserine, does not inhibit the formation of hydrogen sulphide by pantothenate-deficient yeast. Since both methionine and $O$-acetylhomoserine inhibit hydrogen sulphide formation by pantothenate-deficient yeast, one might expect inhibition by homocysteine, which is thought to be a metabolic intermediate between 
these compounds. Some inhibition is observed although the result is not clear-cut. Homocysteine can itself give rise to hydrogen sulphide production and, at high concentrations of the amino acid, this obscures the inhibiting effect on reduction of inorganic sulphur compounds. If homocystine is used in place of homocysteine, the expected inhibition is obtained (Table 2).

Table 2. Inhibition by $O$-acetylhomoserine and homocystine of hydrogen sulphide formation by pantothenate-deficient yeast

$\begin{array}{ccc}\begin{array}{c}\text { DL-O-Acetyl- } \\ \text { homoserine (M) }\end{array} & \begin{array}{c}\text { Growth } \\ \text { (g. dry wt/1.) }\end{array} & \begin{array}{c}\text { Hydrogen } \\ \text { sulphide (mg./1.) }\end{array} \\ 0 & 2 \cdot 45 & 2 \cdot 3 \\ 2 \times 10^{-3} & 2 \cdot 35 & 2 \cdot 25 \\ 4 \times 10^{-3} & 2 \cdot 3 & 1 \cdot 55 \\ 10^{-2} & 2 \cdot 3 & 0 \cdot 1 \\ & & \\ \text { DL-Homocystine } & \text { Growth } & \text { Hydrogen sulphide } \\ \text { (M) } & \text { (g. dry wt/l.) } & \text { (mg./1.) } \\ 0 & 2 \cdot 1 & 2 \cdot 8 \\ 2 \times 10^{-3} & 2 \cdot 0 & 1 \cdot 35 \\ 5 \times 10^{-3} & 2 \cdot 0 & 0.62 \\ 10^{-2} & 2 \cdot 1 & 0.25\end{array}$

Strain I 164 was grown $42 \mathrm{hr}$ in basal medium containing $40 \mu \mathrm{g}$. calcium pantothenate/l. The inoculum was also grown in this medium.

Table 3. Effect of methionine on hydrogen sulphide production by Saccharomyces cerevisiae CC 92-I7A

$\begin{array}{cccc}\begin{array}{c}\text { Pantothenate } \\ (\mu \mathrm{g} . / 1 .)\end{array} & \begin{array}{c}\text { DL-Methionine } \\ (\mathrm{M})\end{array} & \begin{array}{c}\text { Growth } \\ \text { (g. dry wt/1.) }\end{array} & \begin{array}{c}\text { Hydrogen sulphide } \\ (\mathrm{mg} / \mathrm{l} .)\end{array} \\ 500 & 10^{-3} & 1 \cdot 9 & 2.45 \\ & 3 \times 10^{-3} & 2.85 & 2.65 \\ & 5 \times 10^{-8} & 2.5 & 0.4 \\ 0 & 10^{-3} & 1 \cdot 7 & 2.5 \\ & 3 \times 10^{-3} & 2.5 & 2 \cdot 4 \\ & 5 \times 10^{-3} & 1 \cdot 65 & 0.15\end{array}$

Growth was for $48 \mathrm{hr}$ in appropriate basal medium with the indicated supplements. The inoculum was grown in basal medium containing $40 \mu \mathrm{g}$. calcium pantothenate $/ 1$. and the normal methionine supplement.

\section{Effect of supplements on hydrogen sulphide production by mutants}

When grown with 5 mM-DL-methionine, mutant CC92-I7A produces relatively little hydrogen sulphide (Table 3). However, if the methionine concentration is decreased, large amounts are formed, even though growth is hardly affected and the pantothenate concentration is well above that required to suppress hydrogen sulphide formation by pantothenate-deficient brewery yeast. Increased hydrogen sulphide production at lower methionine concentration is also shown in the absence of pantothenate (Table 3). With this mutant, added pantothenate does not decrease the amount of hydrogen sulphide formed; in fact it increases it, but this increase can be related to the increased growth.

$O$-Acetylhomoserine inhibits hydrogen sulphide formation by mutant CC92-I7A. It is equivalent to methionine on a molar basis and the effects are additive. Under 
certain conditions, homocysteine decreases the amount of hydrogen sulphide formed (Table 4) but again the fact that this compound is itself a source of hydrogen sulphide obscures its inhibitory action. The effects of homocysteine and methionine, although not additive, are synergistic.

Two different methionine-requiring mutants, ME-3 (Pigg, Spence \& Parks, 1962) and ME-8 (Cherest, Eichler \& de Robichon-Szulmajster, 1969), would not grow on $O$-acetylhomoserine. As with strain CC92-I 7 A, more hydrogen sulphide was produced during growth on 2 mM-DL-methionine than at higher concentrations. The addition of $5 \mathrm{mM}-\mathrm{O}$-acetylhomoserine did not decrease the amount of hydrogen sulphide formed in the presence of $2 \mathrm{mM}$-methionine, suggesting that $O$-acetylhomoserine itself does not inhibit sulphide formation but must first be converted into an active compound, such as methionine. The amount of hydrogen sulphide produced by these mutants growing on $2 \mathrm{mM}-\mathrm{DL}-\mathrm{methionine}$ was the same whether 40 or $1000 \mu \mathrm{g}$. calcium pantothenate/1. was present.

Table 4. Inhibition by $O$-acetyl-homoserine and homocysteine of hydrogen sulphide production by Saccharomyces cerevisiae CC92-I $7 \mathrm{~A}$

$\begin{array}{cccc}\begin{array}{c}\text { DL-Methionine } \\ (\mathrm{M})\end{array} & \begin{array}{c}\text { O-Acetyl- } \\ \text { homoserine (M) }\end{array} & \begin{array}{c}\text { Growth } \\ \text { (g. dry wt/1.) }\end{array} & \begin{array}{c}\text { Hydrogen sulphide } \\ \text { (mg./1.) }\end{array} \\ 2 \times 10^{-3} & 0 & 2.65 & \mathrm{I} \cdot 9 \\ 0 & 2 \times 10^{-3} & 3.2 & \mathrm{I} \cdot 55 \\ 0 & 4 \times 10^{-3} & 2.9 & 0.05 \\ 2 \times 10^{-3} & 2 \times 10^{-3} & 2.45 & 0.05 \\ \text { DL-Methionine } & \text { DL-Homocysteine } & \text { Growth } & \text { Hydrogen sulphide } \\ \text { (M) } & (\mathrm{M}) & \text { (g. dry wt/1.) } & \text { (mg./1.) } \\ 2 \times 10^{-3} & 0 & 3.75 & 1 \cdot 4 \\ 0 & 2 \times 10^{-3} & 4.0 & 0.65 \\ 0 & 4 \times 10^{-3} & 3.65 & 1 \cdot 25 \\ 2 \times 10^{-3} & 2 \times 10^{-3} & 4.8 & 0.55\end{array}$

Growth was for $42 \mathrm{hr}$. in basal medium containing no methionine and $400 \mu \mathrm{g}$. calcium pantothenate/1.

\section{Hydrogen sulphide production by suspensions of non-growing organisms}

Production of sulphide from sulphite or sulphate by non-growing suspensions of mutant CC92-I7A and of pantothenate-deficient brewery yeast was also studied. The buffered suspension contained glucose but no nitrogen source except that introduced by the amino-acid supplement.

With the mutant, methionine, homocysteine, and $O$-acetylhomoserine all stopped hydrogen sulphide formation both from the added sulphite (or sulphate) and from endogenous sulphur compounds (Table 5).

Suspensions of pantothenate-deficient yeast produced more hydrogen sulphide from sulphite (or sulphate) than the mutant, but there was no endogenous formation. Added methionine or $O$-acetylhomoserine inhibited hydrogen sulphide formation, and in every experiment $O$-acetylhomoserine was the more potent inhibitor. Homocysteine itself gave so much hydrogen sulphide that there was no evidence of inhibition of formation by this compound (Table 5).

In experiments in which the suspensions were incubated for $15 \mathrm{~min}$. with actidione before addition of the sulphur source and either methionine or $O$-acetylhomoserine, 
the latter compounds still inhibited sulphide formation. This suggests that they act upon preformed enzymes rather than after incorporation into enzyme formed de novo.

\section{Reduction of thiosulphate to sulphide}

Pantothenate-deficient brewery yeast also forms hydrogen sulphide when thiosulphate is used as the inorganic sulphur source. Hydrogen sulphide production is inhibited by pantothenate or methionine.

It is well known that inorganic sulphur compounds can be oxidized in air to sulphate, so the results on thiosulphate reduction were checked by using mutants of Saccharomyces cerevisiae which are known to be unable to reduce sulphate or sulphite to sulphide (Naiki, 1965). Three such mutants were used with similar results. Pantothenatedeficient mutants produced hydrogen sulphide from thiosulphate and this was inhibited by pantothenate or methionine (Table 6).

Table 5. Inhibition of hydrogen sulphide formation in cell suspensions of Saccharomyces cerevisiae

\begin{tabular}{|c|c|c|c|c|c|}
\hline Yeast strain & $\begin{array}{c}\mathrm{Na}_{2} \mathrm{SO}_{3} \\
\text { (M) }\end{array}$ & $\begin{array}{l}\text { DL-Methionine } \\
\text { (M) }\end{array}$ & $\begin{array}{l}\text { DL-Homo- } \\
\text { cysteine } \\
\text { (M) }\end{array}$ & $\begin{array}{l}\text { DL-O-Acetyl- } \\
\text { homoserine } \\
\text { (M) }\end{array}$ & $\begin{array}{c}\text { Hydrogen } \\
\text { sulphide } \\
(\mu \mathrm{g} .)\end{array}$ \\
\hline \multirow{8}{*}{$\operatorname{Cc} 92-17 A$} & 0 & - & - & - & $2 \cdot 2$ \\
\hline & 0 & $10^{-2}$ & - & - & 0.3 \\
\hline & 0 & - & $\mathrm{IO}^{-2}$ & - & 0.75 \\
\hline & 0 & - & - & $10^{-2}$ & 0 \\
\hline & $10^{-3}$ & - & - & - & $5 \cdot 6$ \\
\hline & $10^{-3}$ & $10^{-2}$ & 一 & - & 0.9 \\
\hline & $10^{-3}$ & - & $10^{-2}$ & - & I.o \\
\hline & $10^{-3}$ & - & - & $10^{-2}$ & 0 \\
\hline \multirow[t]{8}{*}{ II 64} & 0 & - & - & - & 0 \\
\hline & 0 & $10^{-2}$ & - & - & I. 5 \\
\hline & 0 & - & $10^{-2}$ & 一 & 12.5 \\
\hline & 0 & - & - & $10^{-2}$ & 0.9 \\
\hline & $10^{-3}$ & - & - & 一 & $12 \cdot 0$ \\
\hline & $10^{-3}$ & $10^{-2}$ & - & - & $7 \cdot 0$ \\
\hline & $10^{-3}$ & - & $\mathrm{IO}^{-2}$ & 一 & $16 \cdot 0$ \\
\hline & $10^{=3}$ & - & - & $10^{-2}$ & $I \cdot 4$ \\
\hline
\end{tabular}

Incubation was for $3 \mathrm{hr}$ at $30^{\circ}$ using $4.4 \mathrm{ml}$. liquid in shaken $25 \mathrm{ml}$. conical flasks. The I 64 yeast was pantothenate-deficient.

Table 6. Effect of pantothenate and methionine on production of hydrogen sulphide from thiosulphate by Saccharomyces cerevisiae

$\begin{array}{cc}\text { Calcium pantothenate } & \text { DL-Methionine } \\ (\mu \mathrm{g} . / 1 .) & (\mathrm{M}) \\ 40 & 0 \\ 40 & 2 \times 10^{-3} \\ 40 & 4 \times 10^{-3} \\ 40 & 10^{-2} \\ 400 & 0\end{array}$

$\begin{array}{cc}\begin{array}{c}\text { Growth } \\ \text { (g. dry wt } / 1 .)\end{array} & \begin{array}{c}\text { Hydrogen sulphide } \\ (\mu \mathrm{g} . / 1 .)\end{array} \\ \mathbf{I} \cdot 5 & 295 \\ \mathrm{I} \cdot 85 & 135 \\ \mathrm{I} \cdot 5 & 72 \\ \mathrm{I} \cdot 35 & 20 \\ \mathrm{I} \cdot 5 & \text { 10 }\end{array}$

The thiosulphate-requiring mutant 2I was grown for $42 \mathrm{hr}$ in sulphate-free basal medium containing $0.4 \mathrm{~mm}$-sodium thiosulphate. The inoculum was grown with $40 \mu \mathrm{g}$. calcium pantothenate/l. 
Vitamin $B_{6}$-deficient yeast

When Saccharomyces cerevisiae Guinness strains are grown on limiting quantities of vitamin $B_{6}$, they produce small amounts of hydrogen sulphide. This effect is more pronounced with $S$. carlsbergensis NCYC 4228 employed for $\mathrm{B}_{6}$ assays in beer (Fig. 2). A similar effect has been observed by Kodaira, Ito \& Uemura (I958).

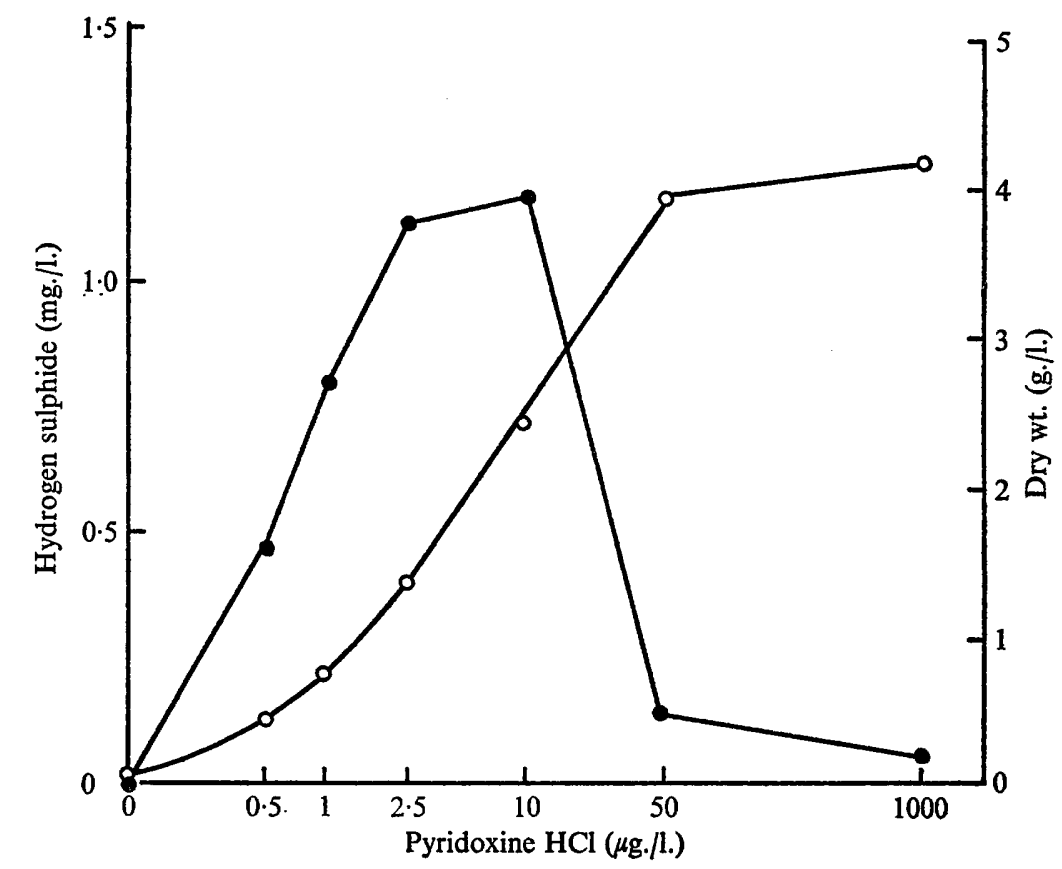

Fig. 2. Effect of pyridoxine on hydrogen sulphide production by Saccharomyces carlsbergensis. Indicates hydrogen sulphide production, and $O$, growth.

Table 7. Hydrogen sulphide production by vitamin $B_{6}$-deficient yeast

$\begin{array}{lcc}\text { Supplement }(5 \mathrm{~mm}) & \begin{array}{c}\text { Growth } \\ \text { (g. dry wt/1.) }\end{array} & \begin{array}{c}\text { Hydrogen sulphide } \\ (\mathrm{mg} . / 1 .)\end{array} \\ \text { None } & 2 & \mathrm{I} \cdot \mathrm{I} 8 \\ \text { DL-Methionine } & 2 \cdot 5 & 0.075 \\ \text { DL-Homocysteine } & 2 \cdot 3 & 0.8 \\ \text { DL-O-Acetylhomoserine } & 2 & 0.2\end{array}$

Saccharomyces carlsbergensis 4228 was grown for $42 \mathrm{hr}$ with $10 \mu \mathrm{g}$. pyridoxine $\mathrm{HCl} / \mathrm{l}$. using an inoculum after three subcultures on basal medium with $5 \mu \mathrm{g}$. pyridoxine $\mathrm{HCl} / \mathrm{l}$.

DL-Methionine at $5 \mathrm{~mm}$, the concentration which inhibits sulphide formation by the mutants or by pantothenate-deficient yeast, inhibits sulphide formation by vitamin $\mathrm{B}_{6}$-deficient yeast. Acetylhomoserine also inhibits hydrogen sulphide formation markedly, and homocysteine inhibits slightly (Table 7).

Saccharomyces cerevisiae CC92-I7A can grow with mM-DL-methionine in the absence of vitamin $B_{6}$ although the vitamin stimulates growth slightly (Table 8). In contrast to the results in vitamin $B_{6}$ assays with normal yeast (Fig. 2), high concentra- 
tions of pyridoxine increase the yield of hydrogen sulphide. With mutant ME-3, pyridoxine has no effect on growth, and neither its absence nor its presence in abnormally high concentrations evokes hydrogen sulphide formation (Table 8).

Excess pantothenate does not prevent hydrogen sulphide formation by vitamin $\mathrm{B}_{6}$-deficient yeast nor can excess pyridoxine overcome pantothenate deficiency. With concentrations of pantothenate greater than those giving maximum yields, but insufficient to inhibit hydrogen sulphide production completely (e.g. $80 \mu \mathrm{g} . / \mathrm{l}$.; see Fig. I), pyridoxine deficiency increases the amount of hydrogen sulphide formed (Table 9). Methionine inhibits production when both vitamins are present in inadequate concentrations as well as when only one is lacking (Table 9).

Table 8. Hydrogen sulphide production by vitamin $B_{6}$-deficient methioninerequiring mutants Saccharomyces cerevisiae CC92-I7A and $M E-3$

$\begin{array}{lcccc}\text { Yeast strain } & \begin{array}{c}\text { DL-Methionine } \\ (\mathrm{M})\end{array} & \begin{array}{c}\text { Pyridoxine HCl } \\ (\mu \mathrm{g} . / 1 .)\end{array} & \begin{array}{c}\text { Growth } \\ (\mathrm{g} . \text { dry wt/1.) }\end{array} & \begin{array}{c}\text { Hydrogen sulphide } \\ (\mathrm{mg} . / 1 .)\end{array} \\ \text { CC92-17A } & 10^{-3} & 0 & 1 \cdot 9 & 2 \cdot 23 \\ & 10^{-3} & 10 & 2 \cdot 0 & 2 \cdot 93 \\ & 10^{-3} & 1000 & 2 \cdot 1 & 4 \cdot 25 \\ \text { ME-3 } & 5 \times 10^{-3} & 10 & 2 \cdot 05 & 0 \cdot 4 \\ & 10^{-3} & 0 & 1 \cdot 1 & 0 \\ & 10^{-3} & 10 & 1 \cdot 1 & 0 \\ & 10^{-3} & 1000 & 1 \cdot \mathbf{I} & 0 \\ & 5 \times 10^{-3} & 10 & 1 \cdot 55 & 0\end{array}$

The basal medium for the experiment contained $400 \mu \mathrm{g}$. calcium pantothenate $/ 1$. but no methionine or pyridoxine. The inoculum had been subcultured twice in medium with $5 \mathrm{mm-}$ DL-methionine, $5 \mu \mathrm{g}$. pyridoxine $\mathrm{HCl} / 1$. and $400 \mu \mathrm{g}$. calcium pantothenate $/ \mathrm{l}$.

Table 9. Hydrogen sulphide production by Saccharomyces cerevisiae II64 deficient in both pantothenate and vitamin $B_{6}$

$\begin{array}{ccccc}\begin{array}{c}\text { Pantothenate } \\ (\mu \mathrm{g} . / 1 .)\end{array} & \begin{array}{c}\text { Pyridoxine } \\ (\mu \mathrm{g} . / 1 .)\end{array} & \begin{array}{c}\text { DL-Methionine } \\ (\mathrm{M})\end{array} & \begin{array}{c}\text { Growth } \\ (\mathrm{g} . / 1 .)\end{array} & \begin{array}{c}\text { Hydrogen sulphide } \\ (\mathrm{mg} . / 1 .)\end{array} \\ 40 & 10 & 0 & 1 \cdot 67 & 2 \cdot 4 \\ 40 & 10 & 10^{-2} & 1 \cdot 98 & \mathrm{I} \cdot 25 \\ 40 & 1000 & 0 & 2 \cdot 28 & 2 \cdot 5 \\ 80 & 10 & 0 & 1 \cdot 85 & 1 \cdot 85 \\ 80 & 10 & 10^{-2} & 2 & 0 \cdot 33 \\ 80 & 1000 & 0 & 2 \cdot 3 & 0 \cdot 7 \\ 1000 & 10 & 0 & 1 \cdot 7 & 0 \cdot 8 \\ 1000 & 10 & 10^{-2} & 2 & 0 \\ 1000 & 1000 & 0 & 2 \cdot 3 & 0\end{array}$

Growth was for $42 \mathrm{hr}$ using a basal medium containing no pantothenate or pyridoxine. The inoculum was grown with $40 \mu \mathrm{g}$. calcium pantothenate/l. in a medium containing no pyridoxine.

\section{Hydrogen sulphide production by Escherichia coli}

As mentioned in the Introduction, the pantothenate effect on hydrogen sulphide production has been observed only in yeasts. In experiments with three pantothenaterequiring mutants of Escherichia coli, very little hydrogen sulphide was detected, but the cultures always reverted to pantothenate independence during the growth period. In E. coli, succinyl-homoserine and not acetylhomoserine is the normal precursor of methionine (Wiebers \& Garner, 1967). In preliminary experiments with the succinate- 
requiring mutant W I485-suc-I of $E$. coli (described by Herbert \& Guest, I968), more hydrogen sulphide is produced at suboptimal succinate concentrations. The inference is that hydrogen sulphide may be produced when succinyl-homoserine is lacking.

\section{DISCUSSION}

The fact that pantothenate deficiency results in the production of hydrogen sulphide by yeasts has been known for some time, but hitherto no satisfactory explanation has been apparent. Kodaira \& Uemura (1960) found that methionine inhibited sulphide production by pantothenate-deficient yeast and suggested that pantothenate was somehow required for the conversion of cysteine to methionine. They suggested that if this could not occur, excess cysteine was converted to hydrogen sulphide by cysteine desulphydrase. Five years later, Okuda \& Uemura (1965) suggested, as a result of testing crude enzyme fractions, that in pantothenate deficiency a sulphite reductase was formed which differed from that in normal cells. Methionine inhibited the formation of this reductase. Our own work on the purification of yeast sulphite reductase from normal and pantothenate-deficient yeast does not support this (Wainwright, 1962, and unpublished observations), and De Vito \& Dreyfus (1964) also reported that methionine did not repress the formation of yeast sulphite reductase. More recently, Aida, Tokuyama \& Uemura (I969) have suggested that the cysteine desulphydrase of baker's yeast is more active in pantothenate-deficient organisms than in normal yeast. They suggested that this was because pantothenic acid deficiency causes a decrease in the ATP content in the organism and that this results in less allosteric inhibition of cysteine desulphydrase by ATP. They suggest that methionine suppresses hydrogen sulphide formation because $S$-adenosylmethionine inhibits cysteine desulphydrase.

The results in the present paper confirm that methionine (or a derivative) plays a key role in the regulation of sulphide production from inorganic sulphur compounds by yeast under three quite different conditions-deficiency of methionine, vitamin $B_{6}$, or pantothenate. These results have been obtained with many strains of yeast and not only those described in the paper. It is also obvious from the results that $O$-acetylhomoserine can be an intermediate in methionine biosynthesis by Saccharomyces cerevisiae and $S$. carlsbergensis. Again the results have been confirmed on several strains additional to those mentioned in the paper. The evidence for the role of $O$-acetylhomoserine in methionine biosynthesis, although strong, has previously been obtained with relatively few strains of Saccharomyces. In the case of the mutant ME-3, which apparently cannot form methionine from acetylhomoserine, it was found that acetylhomoserine did not inhibit hydrogen sulphide formation. The fact that in all other experiments it was at least as active as methionine on a molar basis suggests that it is probably a normal intermediate in Saccharomyces species.

An obvious explanation for the effect of pantothenate is that it is required in the form of coenzyme A for acetylhomoserine synthesis. Thus the same effect can be obtained with growing organisms or in non-growing suspensions by pantothenate or $O$-acetylhomoserine. Pantothenate had little effect on growth of the mutant CC92-I7A and certainly pantothenate deficiency did not increase sulphide production. Obviously if the role of pantothenate is in the formation of acetylhomoserine, and the yeast cannot for other reasons form acetylhomoserine, then pantothenate should have no 
effect either on growth or on hydrogen sulphide formation. Pantothenate likewise had no effect on hydrogen sulphide production by mutants ME-3 or ME-8. $O$-Acetylhomoserine also had no effect so that its precursors would not be expected to show activity.

The part which vitamin $\mathbf{B}_{6}$ plays in the regulation of sulphide formation is less obvious although most of the results suggest an involvement in methionine biosynthesis. Methionine inhibits hydrogen sulphide production by vitamin $\mathbf{B}_{6}$-deficient brewery yeast whether or not it is pantothenate-deficient (Table 9). This amino acid also increases the amount of growth of Saccharomyces cerevisiae (and of $S$. carlsbergensis) at low vitamin $\mathbf{B}_{6}$ concentrations (Table 9), as might be expected if it is an anabolic product of vitamin $B_{6}$ metabolism (Woods, 1953). This is supported by the fact that both the methionine-requiring mutants grew quite well without vitamin $\mathrm{B}_{6}$ (Table 8).

When the mutant CC92-I7A is growing on mM-DL-methionine, hydrogen sulphide is formed to the largest extent in a pyridoxine-rich medium (Table 8) and growth is augmented. This is consistent with the possibility that some methionine is synthesized by the mutant in the presence of pyridoxine since, as shown in Table 3, this is one of the strains of yeast with which methionine at certain concentrations increases hydrogen sulphide production. Mutant ME-3, which cannot grow on $O$-acetylhomoserine, is blocked at one of the later steps in methionine biosynthesis. If pyridoxine cannot be used for methionine biosynthesis in this mutant, it should have no effect on growth or hydrogen sulphide formation. In fact (Table 8) pyridoxine has no effect.

Whilst these results suggest that vitamin $B_{6}$ affects hydrogen sulphide formation because it is involved in methionine biosynthesis, the site of involvement is not obvious. It is known that pyridoxal phosphate is required for the condensation of acetylhomoserine and hydrogen sulphide to form homocysteine (Wiebers \& Garner, 1967). Lack of vitamin $B_{6}$ could result in excretion of hydrogen sulphide because it cannot be utilized for this reaction. However $O$-acetylhomoserine itself inhibits sulphide formation and, whilst it is possible that large amounts of substrate drive the reaction through a mass action effect, it is more likely that vitamin $B_{6}$ does not directly affect homocysteine biosynthesis.

In Saccharomyces cerevisiae, pyridoxal phosphate is required for the formation from serine of the methyl group of methionine (Botsford \& Parks, I969). Vitamin $\mathbf{B}_{6}$ deficiency may cause methionine deficiency through shortage of methyl groups. Again, however, acetylhomoserine should not cure such a defect. It is also possible that the direct effect of vitamin $\mathbf{B}_{6}$ deficiency is on cysteine biosynthesis. Pyridoxal phosphate is required for the formation of cysteine from serine (Schløssmann \& Lynen, 1957) or acetylserine (Wiebers \& Garner, 1967). If hydrogen sulphide cannot be utilized for the reaction, it may be excreted. Moreover, since cysteine represses yeast sulphite reductase formation (De Vito \& Dreyfus, 1964), a deficiency in cysteine biosynthesis might augment hydrogen sulphide production. The effect of methionine in vitamin $B_{6}$ deficiency might be due to the known ability of yeast to form cysteine from methionine. Methionine, however, also has a marked action on hydrogen sulphide formation in conditions other than vitamin $B_{6}$ deficiency, and in these circumstances cysteine biosynthesis is probably not limited.

It is difficult to explain the results with methionine as due to an inhibition of sulphite reduction since, with many pantothenate-deficient strains, appropriate methionine 
concentrations actually increase the amount of sulphide formed (Table r). Moreover pantothenate, $O$-acetylhomoserine and methionine all have no effect on purified yeast sulphite reductase (T. Wainwright, unpublished observations) and the extracts from pantothenate-rich or pantothenate-starved organisms are equally active in reducing sulphite to sulphide (Wainwright, 1962). The pathways for reduction of sulphite (or sulphate) and thiosulphate in yeast are quite distinct (Naiki, 1965). Since pantothenate and methionine inhibit hydrogen sulphide accumulation when yeast (normal or mutant) is grown either on sulphate or on thiosulphate, it is probable that methionine regulates the metabolism of hydrogen sulphide which has been formed rather than that it prevents hydrogen sulphide formation by two independent pathways.

\section{REFERENCES}

Aida, K., Tukoyama, T. \& Uemura, T. (I969). The role of cysteine desulphydrase and cysteine synthase in the evolution of hydrogen sulphide in pantothenic acid deficient yeast. Antonie van Leeuwenhoek 95, Supplement: Yeast Symposium.

BotsFoRD, J. L. \& PARKs, L. W. (I969). Serine transhydroxymethylase in methionine biosynthesis in Saccharomyces cerevisiae. Journal of Bacteriology $97, \mathrm{I} 176$.

BRENNER, M. W., OWADES, J. L. \& GolyZNIAK, R. (I954). Determination of volatile sulphur compounds. Proceedings of the American Society of Brewing Chemists (annual meeting 1953), p. 83. Madison, Wisconsin.

Cherest, H., EICHLER, F. \& DE Robichon-SzUlmajsTer, H. (1969). Genetic and regulatory aspects of methionine biosynthesis in Saccharomyces cerevisiae. Journal of Bacteriology 97, 328.

DAvis, B. D. \& Mrngrolr, E. S. (1950). Mutants of Escherichia coli requiring methionine or vitamin $\mathrm{B}_{12}$. Journal of Bacteriology 60, 17 .

De RoBichon-SzulmajsTer, H. (1967). Régulation du fonctionnement de deux chaînes de biosynthèse chez Saccharomyces cerevisiae: thréonine-méthionine et isoleucine-valine. Bulletin de la Société de Chimie Biologique, Paris 49, I431.

De Robichon-Szulmajster, H. \& Cherest, H. (1967). Regulation of homoserine-O-transacetylase, first steps in methionine biosynthesis in Saccharomyces cerevisiae. Biochemical and Biophysical Research Communications 17, 265.

De Vito, P. C. \& DREYfus, J. (1964). Metabolic regulation of adenosine triphosphate sulfurylase in yeast. Journal of Bacteriology 88, $134 \mathrm{I}$.

Herbert, A. A. \& Guest, J. R. (1968). Biochemical and genetic studies with lysine+methionine mutants of Escherichia coli: lipoic acid and $\alpha$ keto glutarate dehydrogenase less mutants. Journal of General Microbiology 53, 363 .

Kodaira, R. \& Uemura, T. (I960). On the production of hydrogen sulphide by yeast-on the role of pantothenic acid. Koso Kagaku Shinpoziumo 14, 130.

KodaIRA, R., Ito, Y. \& Uemura, T. (1958). On the production of hydrogen sulphide by Sake yeast. I. Pantothenic acid deficiency and the production of hydrogen sulphide. Nippon Nógei-Kagaku Kaishi 32, 49.

LAWRENCE, W. C. \& Cole, E. R. (I968). Yeast sulphur metabolism and the formation of hydrogen sulphide in brewery fermentations. Wallerstein Laboratories Communications 31, 95.

NAGAI, S. \& Flavin, M. (1967). Acetylhomoserine: an intermediate in the fungal biosynthesis of methionine. Journal of Biological Chemistry 242, 3884.

NaIKI, N. (1965). Some properties of sulphite reductase from yeast. Plant and Cell Physiology 6, I79.

OKUDA, S. \& UEMURA, T. (1965). Sulphite reductase system of yeast in relation to pantothenic acid deficiency. Biochimica et Biophysica Acta 97, 154 .

PigG, C. J., Spence, K. D. \& PARks, L. W. (1962). Methionine biosynthesis in yeast. Archives of Biochemistry 97, 491.

RANKINE, B. C. (1963). Nature, origin and prevention of hydrogen sulphide aroma in wines. Journal of the Science of Food and Agriculture 14, 79.

Schlossmann, K. \& LYNen, F. (I957).Biosynthese des Cysteins aus Serin und Schwefelwasserstoff. Biochemische Zeitschrift 328, $59 \mathrm{r}$. 
WAINWRIGHT, T. (1962). Hydrogen sulphide formation by pantothenate deficient yeast. Journal of General Microbiology 28, v.

Wiebers, J. L. \& GARNeR, H. R. (1967). Acyl derivatives of homoserine as substrates for homocysteine synthesis in Neurospora crassa, yeast and Escherichia coli. Journal of Biological Chemistry 242, 5644 .

Woods, D. D. (1953). The integration of research on the nutrition and metabolism of micro-organisms. Journal of General Microbiology 9, 151. 